\title{
The relationship between Taekwondo training habits and injury: a survey of a collegiate Taekwondo population
}

This article was published in the following Dove Press journal:

Open Access Journal of Sports Medicine

22 April 2015

Number of times this article has been viewed

\author{
Natalia Covarrubias' \\ Subir Bhatia ${ }^{2}$ \\ Luis F Campos ${ }^{3}$ \\ Dahn $V$ Nguyen ${ }^{2,3}$ \\ Eric Y Chang ${ }^{1,4,5}$
}

'Department of Physical Medicine and Rehabilitation, University of California Irvine, Irvine, CA, USA; ${ }^{2}$ School of Medicine, University of California Irvine, Irvine, CA, USA; ${ }^{3}$ Institute for Clinical and Translational Science, Irvine, CA, USA; ${ }^{4}$ Department of Anesthesiology and Perioperative Care, University of California Irvine, Irvine, CA, USA; ${ }^{5}$ Reeve-Irvine Research Center, Irvine, CA, USA
Correspondence: Eric Y Chang Department of Physical Medicine \& Rehabilitation, School of Medicine, University of California Irvine Medical Center, Room 3226A, Gillespie Building, 837 Health Science Road, Irvine, CA 92697, USA

Phone + 7|4 4566444

Fax + I 7144566557

Email ericyaochang@gmail.com
Objective: To correlate training habits of Taekwondo (TKD) athletes to risk for injury.

Background: TKD is a Korean marital art that has been growing in popularity, with nearly 2 million individuals practicing the sport in the United States. Because of the combative nature of the sport, injuries are an inherent risk. However, data on proper training habits, types of injuries sustained during training, and recommendations for athletes to avoid injury are lacking. Frequently, studies of TKD evaluate athletes' injuries during tournaments, but most do not evaluate athletes in training.

Hypothesis: Increased training would potentially create more injuries secondary to increased exposure.

Methods: This is a cross-sectional observational survey of 72 collegiate TKD athletes from the Pacific West Sanctioned Taekwondo Tournaments in the 2008-2009 season. Variables analyzed during training and competitions were training sessions per week, workout habits, belt level, years of experience, and characteristics of injury (location, type, mechanism, situation, treatment, and days missed).

Results: TKD training habits of individuals who practiced four or more times per week (odds ratio [OR], $4.5 ; P=0.005$ ) or sparred for more than 2 hours (OR, 8.7; $P=0.003$ ) were associated with significantly increased odds (risk) of sustaining an injury. Those who had more than 3 years of tournament experience were more likely to sustain an injury (OR, 0.198; $P=0.020$ ).

Conclusion: Increased risk for injury with more frequent practice and longer sparring should remind coaches and trainers that monitoring and adjusting the athletes' training schedules and exposure time could decrease the chance of injury. An athlete that has spent more years in tournaments along with high-frequency and long-duration training was associated with greater risk for injuries. Prevention and education about the risk for exposure to injury may may help athletes and trainers promote prevention strategies and adjust an athletes' training and tournament schedules to decrease the risk for injury.

Keywords: sports injuries, martial arts, collegiate athletes, training injuries

\section{Introduction}

Taekwondo (TKD) is a marital art that had been growing in popularity even before its official inclusion in the Sydney 2000 Olympic Games. In the United States, approximately 1.5-2 million people practice martial arts, ${ }^{1}$ the most popular of which is TKD. Athletes participate in full-sparring tournaments, in which points are awarded for punches and kicks to the head and torso. Basic techniques such as punching, kicking, and blocking are performed while moving a short distance or remaining in a stationary position. Training for such tournaments may include contact sparring, noncontact sparring, weight training, and other cardiovascular conditioning. 
Because of the nature of the sport, injuries are an inherent risk. An injury is defined as a stoppage of action to be evaluated by the medical staff. Protective gear is used, and rules are in place in an attempt to protect athletes from serious injury. In the 2012 Summer Olympics, TKD was shown to have higher injury rates than football, BMX, and hockey. ${ }^{2}$ Birrer and Birrer noted that most injuries sustained were mild to moderate in nature. ${ }^{3}$ The most common areas for injury have been the head and lower extremity. ${ }^{4}$ Even with the implementation of protective gear, there appears to be no change in injury rates. ${ }^{5}$ Although injuries during tournaments have been documented, ${ }^{6,7}$ there have been few studies analyzing injuries during training. In a study performed during the 2012 Summer Olympic Games, 66.7\% of injuries to TKD athletes occurred during training. ${ }^{2}$ Kazemi et al evaluated 28 athletes' habits in relation to their injuries that showed no statistical significance. ${ }^{8}$

Frequently, studies of TKD evaluate athletes' injuries during tournaments, but most do not evaluate athletes in training. Because of the lack of information regarding TKD training habits and injuries, this study attempts to fill this knowledge gap both by providing a descriptive summary of TKD training habits, experience, and injury characteristics during training and competition and determining the potential association of training habits and experience with injury during training and competitions. We hypothesized that increased training would potentially create more injuries secondary to increased exposure.

\section{Methods}

During the West Coast Pacific Collegiate Division season from October 2008 to June 2009, athletes from various universities competed in TKD tournaments. At the beginning of two tournaments, the athletes were given a verbal description of the study and told that participation was entirely voluntary. An informed consent in accordance with the UCLA (University of California, Los Angeles) Office for Protection of Research Subjects, Institutional Review Board for research involving human subjects was reviewed and acknowledged by the participants. The comprehensive survey was then handed out to all participants at the tournament, in an unlabeled folder. The questionnaire was modified from previous publications. ${ }^{8}$ The participant then had the entire tournament time to fill out the survey and return it to the head table anonymously. Seven team physicians were on site to answer any questions about participant injuries. Participants were assured the information reported was confidential and that they would not be removed from the competition because of injuries reported in the survey.

The questionnaire asked about various training habits and the number of self-reported injuries during a 12-month period. No reliability or validity information for the instrument is available. Approval for the study was obtained from the institutional review board at the University of California, Los Angeles.

Participants were able to be included in the study if they were participating in a major Pacific West Sanctioned TKD Tournament in the 2008-2009 season. Inclusion criteria included any individual participating in a Pacific West Sanctioned Tournament and dual/tri-meets.

Data on participant characteristics and characteristics of injuries were collected. Logistic regression models were used to examine the association between training habits and experiences with the likelihood of injury. Because of the limited sample size, the outcome is defined as the presence or absence of injury, and each logistic regression model includes a primary independent variable, along with adjustment for sex and age. We also examined height and body mass as potential confounders. However, the results reported are for the parsimonious unadjusted logistic regression model, as variables in age, sex, height, and body mass were not significantly associated with injury. There are, altogether, nine independent variables: practice frequency (fewer than four or more than four times a week), contact practice (spar for 2 or more hours), practice length (more than 1 hour per session), stretching, cooling down, warming up, years of TKD experience ( $<5$ or $\geq 5$ years), years of tournament experience ( $<3$ or $\geq 3$ years), and black belt status (yes/ no). Binary grouping of these independent variables was based on descriptive statistical analysis without prior examination of injury status. T-test and Fisher's exact test were used to determine whether there were any differences in participant characteristics between the binary groups for each variable. Analyses were performed using SAS version 9.3 (SAS Institute, Cary, NC) and JMP version 10.0 (SAS Institute, Cary, NC).

\section{Results}

Seventy-two (90\%) athletes participated in the study. One athlete did not respond regarding their sex. The mean (SD) age was 21 years (3.1 years), with the youngest being 17 years old and the eldest being 27 years old. The mean height was $172.4 \mathrm{~cm}(8.9 \mathrm{~cm})$, and the mean body mass was $65.3 \mathrm{~kg}$ $(9.5 \mathrm{~kg})$. 
On average, the athletes had participated in TKD for 8.2 years ( 7.2 years), with the least being 1 year and the most being 22 years. The athletes participated in 2.1 years' worth of tournaments on average (2.4 years), with the most being 10 years. Most of the athletes surveyed (70.8\%) were black belts (Figure 1). All dan (black belt) levels were grouped into the black belt category. Seven respondents did not comment on their belt level.

The mean duration the athletes participated in training was 2 hours ( 0.8 hour) each session, 4 days (1.2 days) a week. Of those practices, an average of 1.1 hours ( 0.5 hour) was spent in contact. Eight (23\%) of the 35 participants said they did two workouts back-to-back, and 52 (72\%) of the 72 athletes stated they performed workouts outside of their TKD training. Approximately half (45\%) of the athletes would practice against medical advice, and $54(77 \%)$ practiced with chronic injuries.

There was no difference in age or sex between each binary group with the exception that there were more females in the group that spent less than 1 hour per session training than in the group that spent more than 1 hour per session training. Specifically, $55.6 \%$ of females compared with $29.6 \%$ of males practiced 2 or more hours $(P=0.045)$. Individuals with black belts tended to be slightly taller (mean, $174 \mathrm{~cm}$; SD, 9.24) than those without (mean, $169.4 \mathrm{~cm}$; SD, 7.58; $P=0.049$ ). The average body mass of individuals who warm up was 67.2 $\mathrm{kg}(9.1 \mathrm{~kg})$ compared with $61.4 \mathrm{~kg}(9.5 \mathrm{~kg})$ for individuals who did not warm up $(P=0.03)$. Thus, we adjusted for height and weight, which may confound the relationship between

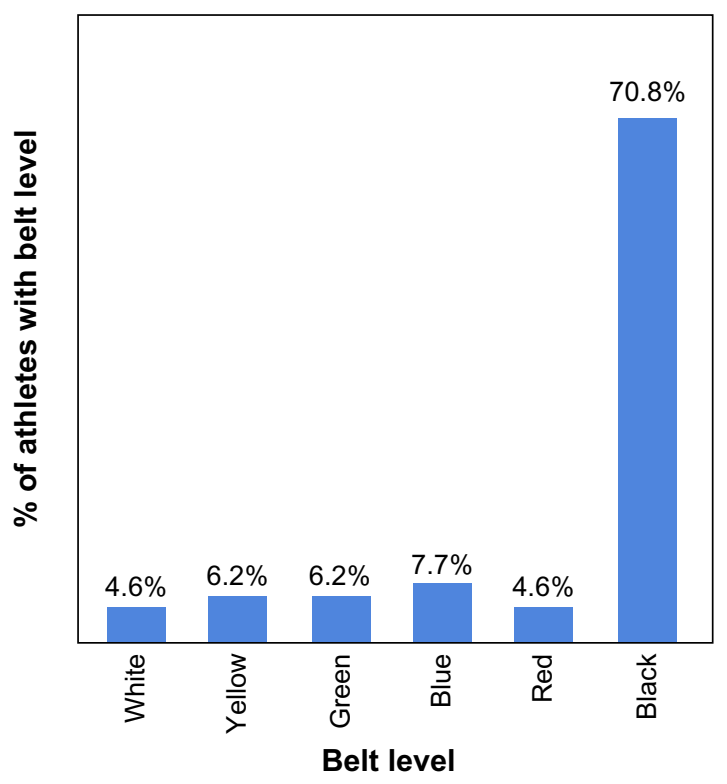

Figure I Belt level $(n=65)$. training habits and experience with the likelihood of injury (see "Methods" section).

We observed higher odds of injury among athletes who had more than 3 years of tournament experience (odds ratio [OR], 0.198; 95\% confidence interval [CI], 0.05-0.76; $P=0.020$ ). Those with more experience among athletes with black belts or who had more than 5 years of TKD experience were not at higher likelihood of having injuries (Table 1).

Stretching, warming up, and cooling down were associated with reduced injury risk (Table 1); in addition, wearing gear during practice and increasing protective gear when injured are noted in Table 2. Athletes who practice 2 or more hours per session were not more likely to have an injury than those who practice less than 2 hours per session. However, athletes who practice four or more times per week did have higher odds of having an injury (OR, 4.5; 95\% CI, 1.6-12.8) compared with individuals who practice fewer than four times per week. In addition, athletes who spar longer than 2 hours have higher odds of having an injury (OR, 8.7; 95\% CI, 2.0-36.6) than those who spar 2 or fewer hours ( $P=0.003$ ).

A total of 80 injuries were reported. The average number of injuries per person over 12 months was two. The highest number was five injuries per person, experienced by six athletes (Table 3). For injuries that required the athlete to seek medical treatment or take time off, the average time off was 8.21 days (18.9 days), with a maximum of 90 days. In terms of mechanism of injury, the most commonly injured body part was the lower extremity (83.7\%), upper extremity (12.5\%), and the head (3.7\%) (Figure 2). The foot was the most frequent site of injury (30\%), followed by the ankle $(11.5 \%)$ and knee (10.8\%) (Table 4). Contusions were the

Table I Association between training habits and experience with injury

\begin{tabular}{|c|c|c|c|}
\hline Training habits & $\begin{array}{l}\text { Odds } \\
\text { ratio }\end{array}$ & $\begin{array}{l}95 \% \text { confidence } \\
\text { interval }\end{array}$ & P-value \\
\hline \multicolumn{4}{|l|}{ Training frequency and sparring } \\
\hline $\begin{array}{l}\text { Practice four or more } \\
\text { times per week }\end{array}$ & 4.499 & $1.585-12.773$ & 0.0047 \\
\hline Spar 2 or more hours & 8.708 & $2.073-36.576$ & 0.0031 \\
\hline Practice $>$ I hour/session & 0.586 & $0.213-1.617$ & 0.3023 \\
\hline \multicolumn{4}{|c|}{ Preparatory and postexercise habits } \\
\hline Always warm up & 1.32 & $0.453-3.848$ & 0.6106 \\
\hline Always cool down & 3.325 & $0.615-17.989$ & 0.1630 \\
\hline Always stretch & 0.684 & $0.237-1.977$ & 0.4834 \\
\hline \multicolumn{4}{|l|}{ Experience } \\
\hline Experience $<5$ years & 0.522 & $0.194-1.402$ & 0.1970 \\
\hline $\begin{array}{l}\text { Tournament } \\
\text { experience }<3 \text { years }\end{array}$ & 0.198 & $0.05 \mathrm{I}-0.775$ & 0.0200 \\
\hline Have black belt & 1.46 & $0.538-3.962$ & 0.4577 \\
\hline
\end{tabular}


Table 2 Training habits, $\mathrm{n}(\%)$

\begin{tabular}{llllll}
\hline Habit & Never & Occasionally & Sometimes & Often & Always \\
\hline Stretch & $0(0 \%)$ & $0(0 \%)$ & $5(7 \%)$ & $19(26 \%)$ & $48(67 \%)$ \\
Warm-up & $0(0 \%)$ & $5(7 \%)$ & $5(7 \%)$ & $11(15 \%)$ & $51(71 \%)$ \\
Cool-down & $3(4 \%)$ & $15(21 \%)$ & $18(25 \%)$ & $26(36 \%)$ & $10(14 \%)$ \\
Wear gear & $1(1 \%)$ & $4(6 \%)$ & $22(31 \%)$ & $32(44 \%)$ & $13(18 \%)$ \\
Increase gear & $6(8 \%)$ & $12(17 \%)$ & $20(28 \%)$ & $17(24 \%)$ & $16(23 \%)$ \\
\hline
\end{tabular}

main injury sustained (41.7\%), followed by sprains $(22.6 \%)$, strains $(13.9 \%)$, and fractures $(11.3 \%)$. Concussions were reported in only $2.6 \%$ of the athletes during the 12 -month period (Table 5).

Sparring was the cause of $70 \%$ of the injuries reported, followed by drills (27\%) (Figure 3). In addition, 64\% (51) of athletes cited an attack as the cause, whereas 36\% (29) reported defense as the cause. Kicking caused 88\% (87) of injuries, trailed by cross training (8\%), clinching (3\%), and evasion (1\%). Of those athletes who reported specific kicks as the reason for their injury $(n=60), 82 \%$ reported a roundhouse kick as the principal cause of injury, followed by an axe kick (7\%). Injury during practice accounted for $77 \%$ (79) of all the injuries; competitions accounted for 23\% (24).

Of the injuries causing the athlete to seek treatment $(n=45), 31$ participants $(28 \%)$ visited a doctor's office, whereas 10 participants ( $9 \%$ ) sought advice from their trainer and 4 participants (4\%) sought advice from an emergency medical technician.

\section{Discussion}

Participation in TKD carries a known risk for injury because of the physical contact involved. This study looked at different training habits to correlate them to injuries, as this may help us understand the current training habits of collegiate athletes and their rates of injury.

Various subgroups of TKD have been noted to be at a higher risk for injury, such as heavier athletes, ${ }^{9}$ professional athletes, ${ }^{10}$ and collegiate athletes, ${ }^{11}$ although these findings have not been found to be consistent. In a meta-analysis by Lystad et al, no difference in injuries was present between sexes or age groups, ${ }^{12}$ whereas Pieter et al found increased

Table 3 Injuries reported per athlete $(n=72)$

\begin{tabular}{lll}
\hline Injuries & Athletes reporting & Percentage of injuries \\
\hline 0 & 17 & 22.97 \\
1 & 24 & 32.43 \\
2 & 10 & 13.51 \\
3 & 9 & 12.16 \\
4 & 8 & 10.81 \\
5 & 6 & 8.11 \\
\hline
\end{tabular}

injuries in females compared with males. ${ }^{13}$ Differences in injury rates between males and females point to an anatomical variation, resulting in the disparity. This has not been found to be the case in other reviewed studies ${ }^{14}$ or in our study. In addition, our study found no statistically significant difference in injury according to age, body mass, height, and belt level individually. TKD has been included in larger studies as just one of many martial arts. ${ }^{15}$ Zetaruk et al investigated predictors of injury in five martial art forms and correlated older age, more experience, and high training frequency to an increased risk for injury. ${ }^{16}$ Rainey investigated injuries in mixed martial arts and noted that those with lower belt rankings had significantly more injuries than professional fighters. ${ }^{17}$ Our study did not find belt ranking a factory for injury. Instead, it showed that athletes with more than 3 years of experience in tournaments were more likely to sustain an injury. When athletes are exposed to tournaments, they are more likely to sustain an injury, as when they are training they are in a protected environment and not subjected to the variability of competitions.

Injuries during the 12-month period averaged two injuries per athlete. The lower extremity was the most commonly

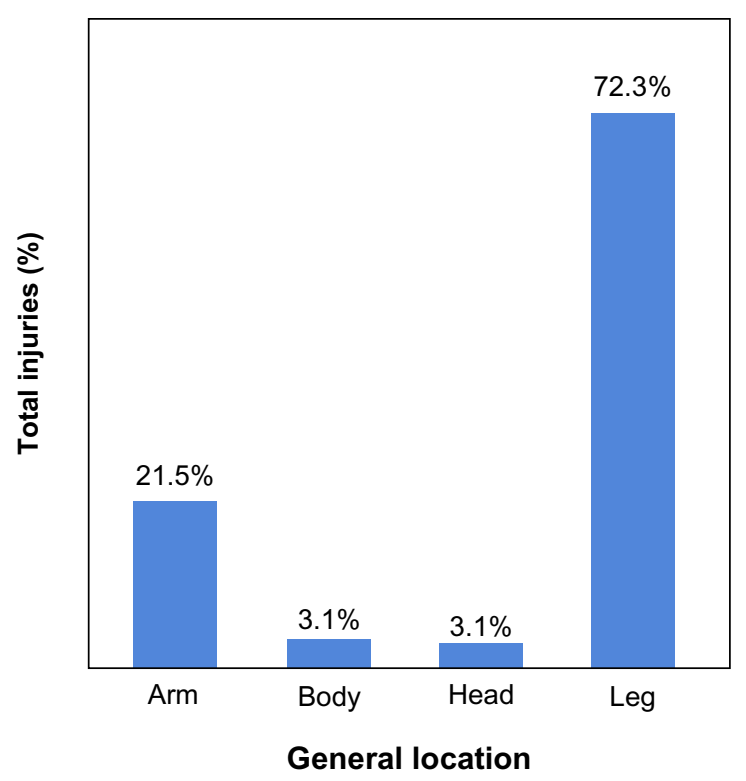

Figure 2 General location of injury $(n=\mid 30)$. 
Table 4 Location of injuries

\begin{tabular}{lll}
\hline Location & Number & Percentage of injuries \\
\hline Foot & 39 & 30.00 \\
Ankle & 15 & 11.54 \\
Knee & 14 & 10.77 \\
Thigh & 10 & 7.69 \\
Hand & 9 & 6.92 \\
Upper arm & 9 & 6.92 \\
Shin & 8 & 6.15 \\
Leg & 5 & 3.85 \\
Head & 3 & 2.31 \\
Wrist & 3 & 2.31 \\
Elbow & 2 & 1.54 \\
Finger & 2 & 1.54 \\
Forearm & 2 & 1.54 \\
Hip & 2 & 1.54 \\
Abdomen & 1 & 0.77 \\
Calf & 1 & 0.77 \\
Groin & 1 & 0.77 \\
Jaw & $\mathrm{I}$ & 0.77 \\
Midback & $\mathrm{I}$ & 0.77 \\
Shoulder & $\mathrm{I}$ & 0.77 \\
Toe & $\mathrm{I}$ & 0.77 \\
\hline
\end{tabular}

involved area, followed by the upper extremity. This finding is consistent with that reported by some other studies. ${ }^{10,18-20}$ However, some studies found the head to be the most commonly affected body part., ${ }^{4,512}$ These differences may be a result of the fact that most of the studies published analyzed data from athletes who were injured during tournaments, and not during training. This may be because participants in tournaments attempt to gain the most points possible, by targeting kicks to the head. In addition, participants may be practicing techniques that are more aggressive in order to win, resulting in high injury rates.

Contusions were the most frequent injury, followed by sprains, strains, and fractures; this also has been fairly consistent in the literature. ${ }^{4,5,12,14,21}$ Concussions only occurred in three of our athletes, which seems low compared with the aforementioned studies citing the head as the most commonly injured body part. This again may have to do with the fact that we focused on all injuries, not just injuries sustained during

Table 5 Type of injury sustained $(n=|| 5)$

\begin{tabular}{lll}
\hline Injury & Number of injuries & Percentage of injuries \\
\hline Contusion & 48 & 41.74 \\
Sprain & 26 & 22.61 \\
Strain & 16 & 13.91 \\
Fracture & 13 & 11.30 \\
Other & 7 & 6.09 \\
Concussion & 3 & 2.61 \\
Dislocation & 2 & 1.74 \\
\hline
\end{tabular}

Notes: Other: muscle cramp (I), shin splints (I), bursitis (I), fasciitis (I), meniscal tear $(\mathrm{I})$, tendonitis $(\mathrm{I})$, nerve damage $(\mathrm{I})$.

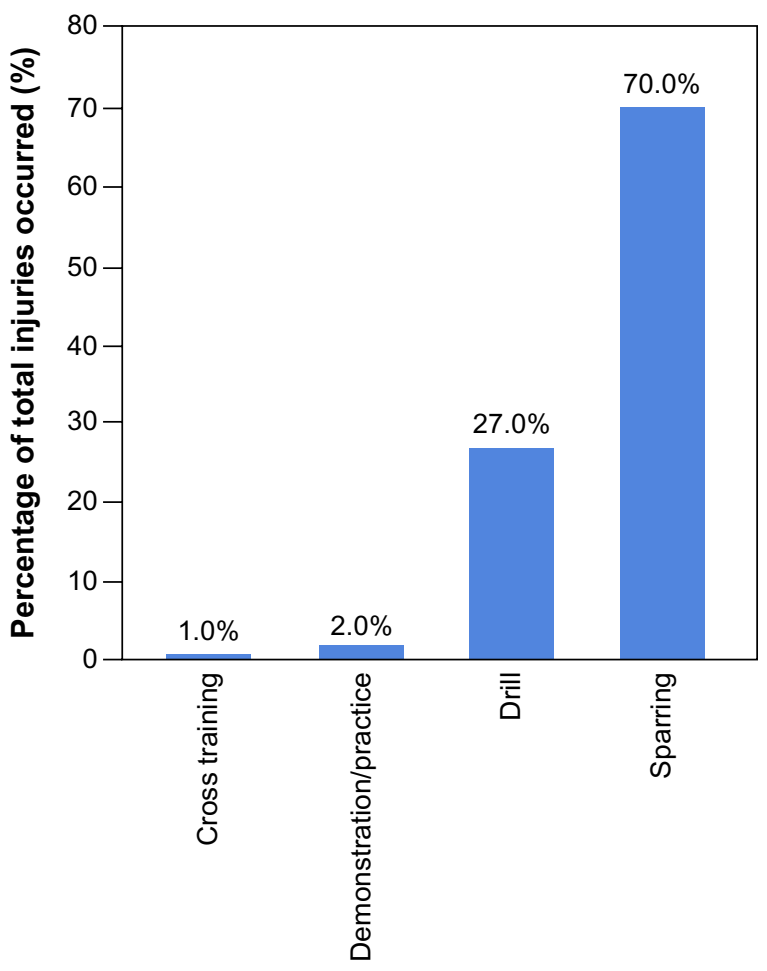

Setting

Figure 3 Setting of injury $(n=100)$.

tournaments. Lower reports of concussions may also be a result of the fear of the athletes that they would be stopped from playing. The risk associated with unreported concussions can have long-term consequences if not monitored or treated appropriately.

Sparring caused more injuries than drills in this study. Attacking was also the cause of more injuries than defending. Kicking was the main mechanism behind injury, specifically a roundhouse kick more than an axe kick, which is characterized by a straightened leg descending onto an opponent. By drawing conclusions that most injuries were caused by kicks and attacking, it can be inferred that more aggressive athletes would be more prone to injuries, as they would be engaging in more "offensive" actions. Most injuries occurred during practice compared with in competitions. This may be explained by the increase in exposure time during training compared with competitions. Athletes may also try different maneuvers during training that may cause injury when they are not as well trained.

Stretching, warming up, cooling down, and wearing gear did not correlate to a decrease in injuries, which is consistent with previous studies. ${ }^{8}, 10$ The use of padding during practice and tournaments had not been shown to decrease injury rates in other studies ${ }^{5}$ and may provide more benefit to the athlete producing the kick than the recipient. ${ }^{15}$ 
Practicing four or more times a week and sparring for 2 or more hours per practice had a statistically significant effect on increasing injuries. Zetaruk et al had found a positive correlation between training hours per week and number of injuries in young karate practitioners. ${ }^{22}$ Studies of other contact sports similarly suggest that increased risk for injury occurs with increased hours of practice; for instance, rugby players who practiced more than 40 hours a week had $54 \%$ more risk for injury than those who practiced fewer hours. ${ }^{23}$ Our results may be explained by increased exposure time, especially if this time is spent sparring. Although this study found no statistically significant effect of belt level on injuries, Rainey demonstrated that athletes with lower belt rankings were more prone to injury. ${ }^{17}$ It is possible that our finding may deal with the fact that the majority of participants $(70 \%)$ were black belts.

\section{Limitations of the study}

We conducted a survey asking athletes to recall injuries that occurred within 12 months. Therefore, errors associated with recall cannot be ruled out. The data we presented are likely an underestimation of the actual injuries, and the athletes may not have fully disclosed all injuries in fear that they would not be allowed to compete if they did. Moreover, Birrer found that $60 \%$ of injuries went unreported. ${ }^{24}$ In an effort to minimize underreporting, our participants were assured that the information collected was kept confidential and would not be used to keep them from participating in the tournament. Selection bias may result from those with no injuries feeling no need to fill out a survey regarding injury. Because the survey requested information about training habits and injuries during the same period, responses regarding training habits could have been inaccurate for injured athletes, and thus not adequately show preinjury habits. Training habits are hard to document, as they may evolve as the athlete learns and improves their techniques, especially in novice athletes. Furthermore, other potential confounding factors beyond those we examined in this study may also explain the risk of having an injury. Finally, although we found statistically significant associations of practice frequency per week, sparring length, and tournament experience with the risk of having an injury, the corresponding estimated confidence intervals are wide, indicating lack of precision because of the relatively small sample size.

\section{Conclusion}

TKD is a popular and growing sport in the United States. Similar to any other contact sport, it is a safety risk to athletes who participate. Injuries such as contusions, strains, and sprains are common. Training habits such as stretching, cooling down or warming up, years of experience, and belt level do not seem to have an effect on injuries. Athletes who practice four or more times per week, spar more than 2 hours at practice, or have 3 or more years of tournament experience are at an increased risk of sustaining an injury. This should remind coaches and trainers that monitoring and adjusting the athletes' training schedules and exposure time during sparring could decrease the risk for injury. In addition, participating in tournaments only when training is optimized may limit injuries. Athletes should be educated about these risks, be more vigilant of injuries during their training, and feel comfortable having a dialog about their injuries and treatments with their coaches and training staff. Thus, with greater preparation in the weight room, classroom education on prevention of injury, and emphasis on balance and motor-neural interface, training will likely reduce injury. In addition, increased awareness of risk for injury, as well as reviewing the beneficial use of protective gear with users, will likely reduce injury.

\section{Acknowledgments}

We acknowledge the support of Edward Kim, DO; Shawn Hsieh, MD; Sujin Lee, MD; Woojae Kim, MD; and Quynh Pham, MD, for their help in gathering data for the manuscript, as well as Rita Peterson and Szu-Yun Leu, PhD, who assisted with statistical analysis and data quality. This work was supported in part by grant K12 HD001097 (E.C.) and grant UL1 TR000153 (E.C., D.V.N., L.C.) from the National Center for Advancing Translational Sciences.

\section{Disclosure}

The authors report no conflicts of interest in this work.

\section{References}

1. Oler M, Tomson W, Pepe H, Yoon D, Branoff R, Branch J. Morbidity and mortality in the martial arts: a warning. J Trauma. 1991;31(2): 251-253.

2. Engebretsen L, Soligard T, Steffen K, et al. Sports injuries and illnesses during the London Summer Olympic Games 2012. Br J Sports Med. 2013;47(7):407-414.

3. Birrer R, Birrer CD. Martial arts injuries. Phys Sportsmed. 1982;10: 103-108

4. Kazemi M, Chudolinski A, Turgeon M, Simon A, Ho E, Coombe L. Nine year longitudinal retrospective study of Taekwondo injuries. J Can Chiropr Assoc. 2009;53(4):272-281.

5. Burke DT, Barfoot K, Bryant S, Schneider JC, Kim HJ, Levin G. Effect of implementation of safety measures in tae kwon do competition. $\mathrm{Br} \mathrm{J}$ Sports Med. 2003;37(5):401-404.

6. Zemper ED, Pieter W. Injury rates during the 1988 US Olympic Team Trials for taekwondo. Br J Sports Med. 1989;23(3):161-164.

7. Kazemi M, Pieter W. Injuries at the Canadian National Tae Kwon Do Championships: a prospective study. BMC Musculoskelet Disord. 2004;5:22. 
8. Kazemi M, Shearer H, Choung YS. Pre-competition habits and injuries in Taekwondo athletes. BMC Musculoskelet Disord. 2005;6(1):26.

9. Beis K, Pieter W, Abatzides G. Taekwondo techniques and competition characteristics involved in time-loss injuries. J Sports Sci Med. 2007; 6(CSSI-2):45-51.

10. Schlüter-Brust K, Leistenschneider P, Dargel J, Springorum HP, Eysel P, Michael JW. Acute injuries in Taekwondo. Int J Sports Med. 2011;32(8):629-634.

11. Chang E, Fish DE, Hsieh S, et al. Epidemiology, Type, Location, and Mechanism of Injury in a Major Collegiate Taekwondo Tournament. Poster Number 130, presented at: American Academy of Physical Medicine and Rehabilitation 70th Annual Assembly; October 22-25; 2009; Austin, TX. PM\&R. 2009;(9 Supplement):s160-161.

12. Lystad RP, Pollard H, Graham PL. Epidemiology of injuries in competition taekwondo: a meta-analysis of observational studies. J Sci Med Sport. 2009;12(6):614-621.

13. Pieter W, Van Ryssegem G, Lufting R, et al. Injury situation and injury mechanism at the 1993 European Taekwondo Cup. J Hum Mov Stud. 1995;28:1-24.

14. Pieter W, Zemper ED. Injury rates in children participating in taekwondo competition. J Trauma. 1997;43(1):89-95.

15. Birrer RB. Trauma epidemiology in the martial arts. The results of an eighteen-year international survey. Am J Sports Med. 1996;24(6) (Suppl):S72-S79.
16. Zetaruk MN, Violán MA, Zurakowski D, Micheli LJ. Injuries in martial arts: a comparison of five styles. Br J Sports Med. 2005;39(1):29-33.

17. Rainey CE. Determining the prevalence and assessing the severity of injuries in mixed martial arts athletes. N Am J Sports Phys Ther. 2009;4(4):190-199.

18. Pieter W, Fife GP, O’Sullivan DM. Competition injuries in taekwondo: a literature review and suggestions for prevention and surveillance. $\mathrm{Br}$ J Sports Med. 2012;46(7):485-491.

19. Feehan M, Waller AE. Precompetition injury and subsequent tournament performance in full-contact taekwondo. Br J Sports Med. 1995; 29(4):258-262.

20. Phillips JS, Frantz JM, Amosun SL, et al. Injury surveillance in Taekwondo and judo during physiotherapy coverage of the seventh All Africa Games. SA J Physiother. 2001;57:32-24.

21. Lystad RP, Graham PL, Poulos RG. Exposure-adjusted incidence rates and severity of competition injuries in Australian amateur taekwondo athletes: a 2-year prospective study. Br J Sports Med. 2013;47(7): 441-446.

22. Pieter W. Martial arts injuries. Med Sport Sci. 2005;48:59-73.

23. Chalmers DJ, Samaranayaka A, Gulliver P, McNoe B. Risk factors for injury in rugby union football in New Zealand: a cohort study. $\mathrm{Br} J$ Sports Med. 2012;46(2):95-102.

24. Birrer RB, Birrer CD. Unreported injuries in the martial arts. Br J Sports Med. 1983;17(2):131-133.
Open Access Journal of Sports Medicine

\section{Publish your work in this journal}

Open Access Journal of Sports Medicine is an international, peer-reviewed, open access journal publishing original research, reports, reviews and commentaries on all areas of sports medicine. The manuscript management system is completely online and includes a very quick and fair peer-review system.

\section{Dovepress}

Visit http://www.dovepress.com/testimonials.php to read real quotes from published authors. 